\title{
Políticas educacionais na formação da professora dos anos iniciais do Ensino Fundamental em cursos de licenciatura
}

- Leandra Martins de Oliveira*

\section{Resumo}

Este texto discute as políticas públicas sobre a formação das professoras dos anos iniciais do Ensino Fundamental, em nível superior, expressadas em legislações e reformas curriculares. Aponta as políticas educacionais para implementar essa formação em cursos de Pedagogia e Normal Superior e suas repercussões na comunidade educacional, abrangendo os seguintes aspectos: 1) o contexto histórico no qual esse debate vem-se construindo e as configurações que vêm assumindo ao longo das políticas educacionais e dos movimentos dos educadores; 2 ) as diretrizes curriculares nacionais exaradas sob influência desse contexto, que implicam mudanças relevantes nas propostas dos cursos de Pedagogia e Normal Superior. Dessa forma, objetiva compreender as propostas atuais para a formação da professora dos anos iniciais do ensino fundamental num contexto marcado por lutas concorrenciais e pelo desenvolvimento da sociedade brasileira. Finaliza com reflexões sobre a melhoria educacional declarada nas leis e diretrizes e sobre o discurso de formação ampla adotado pelas políticas públicas vigentes.

Palavras-chave: Políticas educacionais. Formação de professores. Diretrizes curriculares.

\section{Educational policies on primary school teacher's education In teaching courses \\ Abstract}

This article discusses public policies on primary school teacher education at university level expressed in legislations and curricular reforms. It also points out educational policies to implement teacher education in "Pedagogy" and "Normal Superior" courses and it's repercussions on the educational community; comprising the following aspects: 1) historic context in which this debate has been constructed and the configurations it has been assuming during educational

\footnotetext{
Mestre e Especialista em Educação Tecnológica, CEFET/MG; Graduada em Pedagogia - UEMG; pesquisadora do LACTEA/CEFET/MG; Professora de $1^{\circ}$ e $2^{\circ}$ ciclo da Rede Municipal de Belo Horizonte. E-mail: leiama2005@yahoo.com.br.
} 
policies and educators movements, 2) the national curriculum drafted under influence of this context which implies on relevant changes on the "Pedagogy" and "Normal Superior" course proposals. We aim to comprehend the present proposals for primary school teacher education in the context characterized by competitive contests and the development of Brazilian society. The article finalizes with reflections on educational improvement declared in laws and on the discourse on broad education adopted by public policies in vigor.

Keywords: Educational policies. Teacher education. National curriculum.

\section{Politicas educacionales en la formación de la profesora de los años Iniciales de la} enseñaza fundamental en cursos de licenciatura.

\section{Resumen}

Este texto discute las políticas públicas sobre la formación de las profesoras de los años iniciales de la enseñaza fundamental, en nivel superior, expresadas en legislaciones y reformas curriculares. Apunta las politicas educacionales para implementar esa formación en cursos de Pedagogía y Normal Superior y sus repercusiones en la comunidad educacional, abarcando los siguientes aspectos: 1) el contexto histórico en el cual el debate viene construyéndose y las configuraciones que viene asumiendo a lo largo de las políticas educacionales y de los movimientos de los educadores. 2) las directrices curriculares nacionales labradas bajo influencia de ese contexto, que implican cambios relevantes en las propuestas de los cursos de Pedagogía y Normal Superior. De esa forma, objetiva comprender las propuestas actuales para la formación de la profesora de los años iniciales de la enseñanza fundamental en un contexto marcado por concurrencias y por el desarrollo de la sociedad brasileña. Finaliza con reflexiones sobre la mejoría educacional declarada en las leyes y directrices y sobre el discurso de formación amplia adoptado por las políticas públicas vigentes. Palabras clave: Politicas educacionales. Formación de profesores. Directrices curriculares.

\section{Introdução}

Por muitos anos a formação das professoras dos anos iniciais do Ensino Fundamental (a professora primária) ${ }^{1}$ foi oferecida nas Escolas Normais - posteriormente denominadas cursos de magistério -, em nível secundário ou de $2^{\circ}$ grau.

\footnotetext{
${ }^{1}$ Embora ciente das regras gramaticais, refiro-me ao corpo discente sempre no feminino, uma vez que a presença da mulher nos anos iniciais do Ensino Fundamental é predominante, refletindo questões de gêneros amplamente discutidas em pesquisas da área.
} 
A importância da formação das professoras dos anos iniciais do Ensino Fundamental em cursos de graduação já havia sido levantada no Manifesto dos Pioneiros da Educação Nova, que defendia formar o espírito pedagógico de todos os professores em nivel superior, em instituições incorporadas às universidades. Segundo Cury (2003), essa demanda não teve sequência, mesmo com iniciativas de algumas Universidades Brasileiras, como a Universidade do Distrito Federal (1935), que foi a escola pioneira na elevação dos estudos pedagógicos ao nível universitário e a Escola de Professores de Anísio Teixeira, primeira formadora de professoras primárias em nivel superior. Destarte, a Escola Normal prevaleceu inabalável por muitos anos, sendo a principal referência para a formação das professoras primárias, apesar da existência dos cursos de Pedagogia desde 1939.

Depois de um período marcado pelo tecnicismo da década de 1970, a formação das professoras do ensino primário em nível superior se apresenta na pauta dos encontros educacionais com mais ênfase, na década de 1980, tendo a Associação Nacional para a Formação dos Profissionais da Educação (ANFOPE) como sua maior representante. 0 momento era de intensas críticas sobre a educação que se consolidava aos moldes do capitalismo e sobre as formas de intervenção na prática escolar. Clamava-se, também, pela urgente reforma para a melhoria do ensino público, cujo fracasso vinha sendo constatado por todas as instâncias sociais. Segundo Diniz-Pereira (1999, p. 115): "À medida que a reforma na educação básica se consolida, percebe-se que a tarefa de coordenar processos de desenvolvimento e aprendizagem é extremamente complexa e exige, já a partir da própria educação infantil, profissionais com formação superior." Esta visão foi admitida pela Lei de Diretrizes e Bases da Educação Nacional (BRASIL, 1996), doravante LDB, que trouxe intensos debates sobre a formação de professores para a educação básica e, de maneira expressiva, das professoras dos anos iniciais do Ensino Fundamental.

Conforme nos aponta Diniz-Pereira (1999), Freitas (2002), Maués (2003), o contexto de aprovação da LDB/96 foi marcado pelo neoliberalismo, interesse do capital financeiro, diminuição do papel do Estado nas ações, abrindo mais espaço no mercado competitivo. As políticas educativas se veem sob as teses de descentralização e autonomia inscritas no modelo neoliberal, e o sucateamento das instituições públicas de ensino se confronta com uma ampliação de instituições privadas. Esse contexto se torna "terra fértil" para a manifestação de interesses opostos, tornando o debate acerca da formação de professores iniciais em nivel superior objeto de disputas e interesses específicos no interior da própria área (fundamentos, objetivos, princípios) e exterior a ela (instituições públicas versus instituições privadas).

0 conteúdo deste texto abrangerá dois focos de análise: 1) o contexto histórico no qual esse debate vem-se construindo e as configurações que vêm assumindo ao longo das políticas educacionais e dos movimentos dos educadores; 2) as diretrizes 
curriculares nacionais exaradas sob influência desse contexto, que implicam mudanças relevantes nas propostas dos cursos de Pedagogia e Normal Superior. Dessa maneira, busca-se entender a importância desta formação como instrumento de desenvolvimento profissional e valorização do processo educativo, desde que não caia num discurso vazio e isolado das condições reais presentes no exercício da docência.

\section{Consolidando a formação em nível superior ${ }^{2}$}

A primeira regulamentação do curso de Pedagogia, datada de 1939, previa a formação do técnico em educação, em nivel de bacharelado. Desse período até 1968, prevalecia na organização do curso o esquema popularmente conhecido como 3+1: três anos de bacharelado e mais um ano para cursar as matérias pedagógicas (Didática Geral, Didática Especial, Psicologia da educação e Administração escolar), caso o egresso fosse ministrar aulas das disciplinas que compunham o antigo curso secundário (PALMA FILHO, 2004). Esse modelo considerava a formação pedagógica superficial - razão pela qual era oferecida em apenas um ano. 0 importante era um profundo conhecimento dos conteúdos que o professor iria ensinar: "o quê" prevalecendo sobre o "como". O Parecer CFE n. 251/62 (CONSELHO NACIONAL DE EDUCAÇÃO, 1963), estabeleceu para o curso a formação de professores para atuarem nas escolas normais, além dos técnicos de educação (LIBÂNEO; PIMENTA, 1999). 0 modelo de formação " $3+1$ " nos permite constatar duas situações esdrúxulas: a aluna egressa poderia formar futuras professoras primárias nas escolas normais, mas não poderia ser professora primária se não tivesse o magistério ou, como nos aponta Novaes (1992), se formaria uma professora de metodologia do ensino primário, por exemplo, para lecionar tal disciplina na Escola Normal, sem que a mesma tivesse vivenciado alguma experiência da prática educacional nesse nível de ensino.

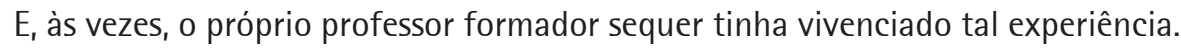

0 prenúncio da formação em nível superior para a docência no ensino primário veio somente em 1969, com o Parecer CFE nº. 252/69 e sua respectiva Resolução CFE $n^{\circ}$. 2/69 que autorizava os cursos de Pedagogia, até então responsáveis pela formação de especialistas técnicos em educação, a habilitar para o exercício da docência nas séries iniciais. Desde então, o curso de Pedagogia oferecia três habilitações distintas: 0 técnico educacional, o professor para as escolas normais e o professor para os anos iniciais do Ensino Fundamental. Esta modalidade visava a atender a um contexto onde a racionalização do trabalho, a execução padronizada de tarefas, exigia a formação de cidadãos treinados para realizarem uma atividade específica, se limitando a ela.

Essa visão suscitou criticas intensas, principalmente a partir da década de 80 , que se fundamentavam no caráter desconfigurador e vazio dos cursos, devido à impossibilidade de se oferecer uma formação sólida tanto para a docência, quanto

${ }^{2}$ Este tópico retoma parte da linha histórica apresentada em Oliveira, L. (2007), ampliando o foco de análise. 
para o técnico educacional. Tais críticas provocaram uma cisão entre aqueles que defendiam a docência como base da formação profissional do pedagogo e aqueles que defendiam a clara distinção entre o trabalho docente e trabalho pedagógico ${ }^{3}$, garantindo, assim, a identidade do pedagogo (LIBÂNEO, 2005; OLIVEIRA, 2006). 0 primeiro grupo conta com a adesão de entidades educacionais lideradas pela ANFOPE e o Fórum de Diretores de Faculdades/Centros de Educação das Universidades Públicas Brasileiras (Forundir). No segundo grupo, destacam-se educadores como Selma Garrido Pimenta, José Carlos Libâneo e Maria Amélia Franco.

Esses grupos vêm publicando seus posicionamentos em relação às teses que defendem e, embora a formação em nivel superior para a docência nas séries iniciais seja uma necessidade reconhecida por ambos, essa dicotomia acaba por fortalecer as entidades oficiais na implementação de concepções fragmentadas acerca do perfil distinto entre professores e especialistas. Estes pensam e elaboram a prática educativa, aqueles executam o que Ihe foi determinado. Segundo Freitas (2002, p.146),

Com isso, estão criadas as condições teóricas e práticas para o surgimento dos novos "capatazes da educação" (FREITAS, 1999), aqueles que, formados sobre bases teóricas mais sólidas no campo específico da teoria pedagógica, tornam-se aptos para orientar os pobres "professores tarefeiros", que por suas condições materiais de existência se defrontam com a impossibilidade de se superarem em sua formação teórica.

A autora salienta que as especificidades da pedagogia defendida por alguns autores deveriam ser ampliadas como componentes de formação de todos os docentes.

Para completar a complexidade na formação superior das professoras dos anos iniciais do Ensino Fundamental, o curso de Pedagogia trazia ainda dilemas inerentes aos cursos de licenciatura. Esses dilemas são assim explicitados por Diniz-Pereira (2006):

- Separação entre disciplinas de conteúdo e disciplinas pedagógicas: o esquema " $3+1$ " não estabelecia o mínimo de articulação entre disciplinas pedagógicas e disciplinas de conteúdo;

- Bacharelado X Licenciatura: essa dicotomia se relaciona à duplicidade de objetivos dos cursos: formar pesquisadores e professores. Autores acusam uma valorização das atividades de pesquisa em relação ao ensino e, conseqüente, a sobreposição do Bacharelado em detrimento da Licenciatura. Tal dicotomia é um reflexo da separação entre ensino e pesquisa no meio acadêmico;

\footnotetext{
3 Trabalho pedagógico: atuação profissional em um amplo leque de práticas educativas. Trabalho docente: forma peculiar que o trabalho pedagógico assume na sala de aula. (LIBÂNEO, 2005, p. 39).
} 
- Desarticulação entre formação acadêmica e realidade prática: a separação entre teoria e prática, talvez seja a causa dessa desarticulação. Esta separação pode ser justificada, segundo alguns autores, pela pouca (ou nenhuma vivência) dos docentes universitários com a realidade dos sistemas de ensino, onde atuarão os futuros educadores e pela forma equivocada como os estágios têm-se configurado nos cursos de formação docente, ou seja, como aplicação da teoria.

Em relação ao curso de Pedagogia, o esquema " $3+1$ " que preparava formadores do então curso normal, mas não habilitava professores das séries iniciais; a fragmentação reforçada pelo parecer Parecer CFE n.252/69 que distinguia professores e especialistas - inclusive pela falta de conteúdo daquele, como nos aponta Cury (2003); a falta de integração entre os cursos e a realidade onde os futuros professores iriam atuar são alguns reflexos desses dilemas, além do isolamento entre os cursos de Pedagogia e as demais licenciaturas.

0 parecer de 1969 não chegou a abalar a estrutura na formação em nível médio, como fez a LDB 9394 (BRASIL, 1996) que, paulatinamente, reduziu os cursos de magistério - e demais cursos técnicos - embora ainda existam escassamente em instituições isoladas ou em programas de capacitação de profissionais leigos. A LDB 9394 (BRASIL, 1996) foi uma resposta às críticas às escolas "pelo insucesso escolar, pelo despreparo dos alunos ao término dos estudos, pela desvinculação dos conteúdos ensinados em relação às novas demandas oriundas do mundo do trabalho assentados no paradigma informacional." (MAUÉS, 2003, p. 91). Para reverter esse quadro, eram necessárias, dentre outras medidas, reformas na formação dos docentes, tendo como um dos elementos constitutivos desse receituário de formação a "universitarização", "que seria uma forma de qualificar melhor essa formação e encaminhá-la para a profissionalização, representaria um aprofundamento dos conhecimentos e um maior domínio no exercício da função." (MAUÉS, 2003, p. 99).

Ao determinar, em seu artigo 62, a preparação dos docentes da educação básica em nível superior, a LDB 9394 (BRASIL, 1996) potencializou o debate acadêmico em torno dos objetivos, princípios e rumos da formação para a docência nas séries iniciais, bem como sua oferta. Criou os Institutos Superiores de Educação (ISE) que poderiam oferecer o Curso Normal Superior (doravante CNS), responsável pela formação dos docentes para a educação infantil e para os anos iniciais do Ensino Fundamental, já que até o momento tal habilitação era oferecida com o adendo de matérias pedagógicas a um curso organizado como bacharelado.

Desde então, o artigo 62 da LDB 9394 (BRASIL, 1996) tem sido criticado por diversos educadores e pelas principais entidades educacionais, tais como a ANFOPE 
e a Associação Nacional de Pós-graduação e Pesquisa em Educação (ANPED). Pimenta (2004) situa a criação desses institutos dentro de uma política governamental de reserva de mercado, onde a garantia da educação básica gratuita à maioria da população acabou contrariando interesses privados. Segundo a autora, para compensar essa defasagem, o governo oferece outra fatia de mercado aos empresários da educação: a formação dos professores em nível superior em institutos particulares. A ANFOPE e ANPED (PALMA FILHO, 2004) argumentam o risco de se fragilizar a formação dos professores, criando institutos que não têm status de universidade - considerada principal local de produção do saber -, além de ter havido um rebaixamento na exigência da titulação de mestres e doutores do corpo docente $10 \%$ nos ISE contra 1/3 exigido nas universidades. Palma Filho (2004) aponta os pontos vulneráveis desses argumentos, respectivamente:

- a formação dos professores já ocorre há muito tempo em instituições de Ensino Superior não universitárias;

- o quantitativo exigido para as universidades é para a totalidade do corpo docente da instituição, e não por curso. Sem contar que a situação atual das Instituições não universitárias não atende a esses requisitos.

Para Freitas (2002, p. 144), os ISE foram criados como instituições de caráter técnico-profissionalizante, cuja expansão visa a responder, com raras exceções,
[...] às demandas de grande parcela da juventude atual por educação em nivel superior, oferecendo-Ihes uma qualifi- cação mais ágil, flexível, adequada aos princípios da pro- dutividade e eficiência e com adequação às demandas do mercado competitivo e globalizado.

Sem dúvida, a LDB 9394 (BRASIL, 1996) impulsionou uma corrida por parte das professoras das séries iniciais, já em exercício, para fazer o curso superior, principalmente, pela interpretação dúbia do artigo $87 \S 4^{\circ}$ que determinava a admissão somente de professores habilitados em nível superior. Assim, o surgimento de vários institutos e programas de formação de férias, após a promulgação da lei, contou com uma considerável clientela que, ignorando a condição de direito adquirido já previsto pela Constituição Federal de 1988 (BRASIL, 1988), acreditava na perda do direito de lecionar, caso não fizesse o curso superior. Além disso, havia um grande contingente de profissionais leigos atuando há vários anos na educação básica, sem sequer terem adquirido a habilitação mínima para tal, e seria impossível simplesmente excluí-los de sua atividade profissional. Infelizmente, ao invés de promover debates e reflexões entre as professoras, acerca da importância de se buscar o curso superior enquanto formação cidadã, aliada à possibilidade de desenvolvimento e melhoria da prática profissional, a lei instaurou um sentimento de obrigação e medo do desemprego entre as docentes. 
Ao longo das determinações legais que se seguiram, o debate intensificou-se. 0 Decreto Federal $n^{\circ}$. 3.276 (BRASIL, 1999), que atribuía a formação de professores exclusivamente aos ISE, desperta indignação dos educadores, cuja pressão levou à imediata retificação do mesmo, dado seu caráter de ilegalidade frente à própria LDB. Assim, em 7 de agosto de 2000, é retificado pelo Decreto nº 3.554 (BRASIL, 2000) que substitui a palavra "exclusivamente" por "preferencialmente". Esta retificação não foi o suficiente para afastar da comunidade educacional as reflexões e denúncias em torno do desmantelamento da universidade pública.

Os ISE ficam então autorizados pelo artigo $1^{\circ}$ da Resolução CP $n^{\circ} .1$ (CONSELHO NACIONAL DE EDUCAÇÃO, 1999) ${ }^{4}$ a oferecerem:

I - curso normal superior, para licenciatura de profissionais em educação infantil e de professores para os anos iniciais do ensino fundamental;

II - cursos de licenciatura destinados à formação de docentes dos anos finais do ensino fundamental e do ensino médio;

III - programas de formação continuada, destinados à atualização de profissionais da educação básica nos diversos níveis;

IV - programas especiais de formação pedagógica, destinados aos portadores de diploma de nivel superior que desejem ensinar nos anos finais do ensino fundamental ou no ensino médio, em áreas de conhecimento ou disciplinas de sua especialidade, nos termos da Resolução CNE n. 2/ 97;

V - formação pós-graduada, de caráter profissional, voltada para a atuação na educação básica.

Segundo o disposto no artigo $6^{\circ}$ da Resolução CP n.1 (CONSELHO NACIONAL DE EDUCAÇÃO, 1999), o CNS teria como função preparar profissionais com as seguintes capacidades:

I - na formação para a Educação Infantil, promover práticas educativas que considerem o desenvolvimento integral da criança até seis anos, em seus aspectos físico, psico-social e cognitivo-lingüístico;

II - na formação para o magistério dos anos iniciais do Ensino Fundamental, conhecer e adequar os conteúdos da língua portuguesa, da matemática, de outras linguagens e

${ }_{4}^{4} 0$ Parecer CP 115/99 (CONSELHO NACIONAL DE EDUCAÇÃO, 1999), aprovado em 10 de agosto de 1999, trata das Diretrizes Gerais para os Institutos Superiores de educação, sendo a fundamentação desta resolução. 
códigos, do mundo físico e natural e da realidade social e política, de modo a assegurar sua aprendizagem pelos alunos a partir de seis anos.

O CNS passou, então, a ser oferecido nos ISE ou por meio de programas especiais, elaborados pelas estatais em parceria com instituições universitárias e possuindo formatos variados - modular, parcelado, telepresencial, à distância - como, por exemplo, o Projeto Veredas ${ }^{5}$, ocorrido no Estado de Minas Gerais. Esses programas, além da habilitação inicial em nível médio, objetivavam ampliar a formação daquelas que já atuavam nas séries iniciais, mas ainda não tinham o curso superior. Uma vez caracterizado como curso de licenciatura, o CNS seria regido por toda a legislação relativa a essa modalidade de ensino, o que significa que seu projeto político pedagógico deve estar de acordo com as Diretrizes Curriculares Nacionais para formação de professores.

Tal como os Institutos Superiores de Educação, o CNS também foi alvo de muitas críticas no meio acadêmico, sendo considerado cursos com pequena ou nenhuma relação com a pesquisa, concretizando uma política aligeirada de formação docente. Libâneo e Pimenta (1999) consideram o curso mera extensão do curso normal de nível médio. A contraproposta desses autores era a formação dos professores para a educação básica nas atuais faculdades de educação, criando um Centro de Formação, Pesquisa e Desenvolvimento Profissional de Professores, destinado à formação de docentes para atuarem da Educação Infantil ao Ensino.

Apesar da resistência acadêmica em relação ao CNS, pesquisas apontaram a qualidade de projetos desenvolvidos em alguns cursos. Dias (2003) verifica a importância do curso na transformação da prática profissional de seus alunos que, em geral, já atuavam nas séries iniciais do Ensino Fundamental. Aponta, também, as atitudes críticas que os alunos mantêm com os conhecimentos teóricos propostos no curso, relacionando-os aos saberes práticos de sua trajetória profissional. Finaliza salientando que mais do que aperfeiçoar sua prática docente,

[...] os alunos vêm reconstruindo seu próprio percurso profissional, a partir de reflexões que levam a uma visão mais ampla da escola e do processo educativo ao desvendamento da profissão docente e das próprias motivações e expectativas em relação à carreira. (DIAS, 2003, p. 134).

Gomes (2005) observa que os saberes profissionais e os conhecimentos construídos pelas alunas do curso, que também já exerciam o magistério, ressignificaram a forma de olhar a criança, de respeitar seus limites e buscar alternativas

\footnotetext{
5 Implantado pela Secretaria de Estado de Minas Gerais e desenvolvido em parceria com várias instituições de ensino superior, caracterizadas como agências formadoras (AFOR). Maior aprofundamento, confira Gomes (2005).
} 
de trabalho. Ambas as pesquisas destacam também o papel do CNS como oportunidade de as alunas se desenvolverem profissionalmente, alcançando melhores possibilidades salariais.

0 contexto atual indica que a permanência do CNS no sistema educacional não contará nem com uma década, dada a promulgação das Diretrizes Curriculares Nacionais para os cursos de Pedagogia (BRASIL, 2006). Pela resolução, as instituições mantenedoras do Curso Normal Superior têm abertura para transformá-los em cursos de Pedagogia, mediante a elaboração de novo projeto pedagógico. Embora não disponha de dados sobre a adesão das Instituições, minha hipótese é que muitos ISE irão aderir ao novo projeto, dada a dificuldade das instituições em manterem seus cursos exclusivamente como cursos Normal Superior (FREITAS, 2002), além da desqualificação acadêmica sofrida pelos cursos. Mais uma vez evidencia-se o caráter transitório e pouco consolidado de muitas políticas públicas, que vêm e vão, sem uma avaliação do seu impacto, de suas implicações na formação do professor e, até mesmo, das contribuições que tal experiência poderia fornecer às novas reformulações curriculares.

Outras investidas do governo para a formação do professor em nivel superior têm sido implementadas através do Plano de Desenvolvimento da Educação (PDE) que objetiva o trabalho colaborativo entre governos federais, estaduais e municipais pela melhoria da qualidade educacional do pais (BRASIL, 2007). No que tange à formação docente, o governo propõe duas frentes de ação: ampliar o acesso ao ensino superior nas universidades públicas federais e apoiar os programas de educação a distância. Quanto à primeira ação, para receber recursos previstos no PDE, as universidades federais precisarão apresentar projetos de reformulação que incluam o aumento de vagas, a ampliação ou abertura de cursos noturnos, a redução do custo por aluno, a flexibilização de currículos, a criação de novas arquiteturas curriculares e ações de combate à evasão. Tais medidas incorporam novos rumos para os cursos de licenciatura, já apontados por Diniz-Pereira (2006). A segunda ação diz respeito à oferta do ensino superior através da educação a distância, concretizada, nesse caso, pela Universidade Aberta do Brasil (UAB) ${ }^{6}$. Com a UAB, espera-se oferecer formação inicial aos professores em efetivo exercício na educação básica pública que ainda não têm graduação. 0 ponto debatido dessa proposta é o privilégio de uma modalidade de educação a distância na formação inicial dos professores em exercício, o que, para Freitas (2007, p. 1214), pode levar a uma massificação da formação docente, conformando os professores

a uma concepção de caráter subordinado, meramente instrumental, em contraposição à concepção de educador de

\footnotetext{
${ }^{6}$ Projeto criado pelo MEC, em 2005 que articula as instituições públicas federais de ensino superior e os CEFETs para levarem o ensino superior aos municípios cuja oferta de ensino superior seja insuficiente ou ausente, na modalidade educação a distância.
} 
caráter sócio-histórico, dos professores como profissionais da educação, intelectuais essenciais para a construção de um projeto social emancipador que ofereça novas possibilidades à educação da infância e da juventude.

Os cursos de formação docente, independente da natureza, devem organizar suas propostas pedagógicas de acordo com as diretrizes nacionais para a formação de professores. Tais diretrizes pretendem superar uma concepção técnico-instrumental, marcada pela distância entre o objeto de estudo, sua expressão escolar e a realidade, pelo tratamento inadequado e hierarquizado dos conteúdos, pela desconsideração das especificidades próprias de cada nível ou modalidade de ensino. Sendo assim, define trajetórias curriculares diferentes do formato tradicional, que serão abordadas no tópico seguinte.

\section{Trajetórias curriculares na formação docente}

Cada vez mais, a formação das professoras dos anos iniciais vem sendo oferecida em nível superior, ainda que se admita a formação em nível médio, na modalidade normal. Uma vez que se concretiza paulatinamente em cursos de licenciaturas, essa formação incorpora os debates e embates da área, que envolve tanto os dilemas anteriormente explicitados por Diniz-Pereira (2006), quanto aqueles relacionados com a discussão da identidade e finalidade do Curso de Pedagogia e Normal Superior. Destarte, a formação em nivel superior incorpora as discussões sobre as Diretrizes Curriculares Nacionais para os cursos de Formação de Professores na educação Básica (doravante DCN)7 e para os cursos de Pedagogia (doravante $\mathrm{DCN}$-Pedagogia) ${ }^{8}$.

A flexibilidade, a inovação curricular, a interdisciplinaridade, o trabalho com pesquisas, a construção de competências para o exercício da docência são aspectos em destaque no conteúdo de ambas as diretrizes. Tais aspectos buscam, segundo a proposta dos documentos, superar uma concepção de formação docente pautada na necessidade de se dominar a técnica, o saber-fazer, reduzindo a tarefa do educador a um executor de ações, preocupado em transmitir o conteúdo. Buscam também incorporar no interior dos cursos a formação de professores autônomos, reflexivos e criativos no exercício da prática educativa, desencadeando um conjunto de reflexões pertinentes à formação da professora da educação infantil e dos anos iniciais do ensino fundamental. No entanto, esses aspectos vêm sendo debatidos nas publicações da área que desenvolvem reflexões sobre a desprofissionalização do magistério, sobre a transposição acrítica da noção de competências para o âmbito educacional ou sobre o lócus de preparação dos profissionais da educação no Brasil (FREITAS, 2002; DINIZ-PEREIRA, 1999).

\footnotetext{
${ }^{7}$ Parecer CNE/CP no. 9/2001; Resolução CNE/CP no. 1/2002.

${ }^{8}$ Parecer CNE/CP n ${ }^{\circ}$. 5/2005; Resolução CNE/CP no. 1/2006.
} 
A noção de competências é entendida nos documentos como a capacidade do profissional em mobilizar os conhecimentos aprendidos e transformá-los em ação, além de ter conhecimento sobre o seu trabalho. No lugar de disciplinas obrigatórias, é apontada uma matriz curricular fundamentada em eixos articuladores das dimensões necessárias na formação profissional, tais como: a dimensão teórico/prática, conteúdos gerais e conteúdos pedagógicos, a disciplinaridade e interdisciplinaridade. A noção de competências tem-se tornado referência para os sistemas de avaliação da educação nacional, tanto do rendimento dos alunos, quanto da eficácia dos cursos de formação, valorizando a dimensão da certificação no âmbito educativo (FREITAS, 2002). Freitas (2002) considera tal noção um retorno às concepções pragmatistas e tecnicistas da década de 1970, agora em um patamar mais avançado.

Em consonância com as DCN, as DCN-Pedagogia tratam das orientações normativas, princípios e procedimentos da formação inicial para

[...] o exercício da docência na Educação Infantil e nos anos iniciais do Ensino Fundamental, nos cursos de Ensino Médio de modalidade Normal e em cursos de Educação Profissional, nas áreas de serviços e apoio escolar, bem como em outras áreas nas quais sejam previstos conhecimentos pedagógicos (CONSELHO NACIONAL DE EDUCAÇÃO, 2006).

Uma vez que as DCN-Pedagogia são instituídas pela Resolução do $\mathrm{CNE} / \mathrm{CP} \mathrm{n}^{\circ} .1$ (CONSELHO NACIONAL DE EDUCAÇÃO, 2006), tem-se a extinção progressiva das habilitações, anteriormente oferecida pelo curso de Pedagogia, que permitiam a atuação dos egressos na administração, planejamento, inspeção, supervisão e orientação educacional. A formação para essas áreas é prevista em caráter de aprofundamento de estudo ou em cursos de pós-graduação. Se oferecida nos cursos de Pedagogia, deve ser comprovada no histórico escolar do egresso sem, no entanto, se configurar como uma habilitação ${ }^{9}$. Em contrapartida, procura-se ampliar a compreensão sobre o conceito de atividade docente, considerada não somente a regência de classe, mas aquelas que englobam:

- planejamento, execução, coordenação, acompanhamento e avaliação de tarefas próprias do setor de Educação;

- planejamento, execução, coordenação, acompanhamento e avaliação de projetos e experiências educativas não escolares;

- produção e difusão do conhecimento científico-tecnológico do campo educacional, em contextos escolares e não escolares (CONSELHO NACIONAL DE EDUCAÇÃO, 2006, p. 7-8).

\footnotetext{
9 Diário Oficial da União, 10 de julho de 2006, Seção I, p. 8. Despacho do Diretor do Departamento de Supervisão do Ensino Superior. Esclarecimentos para a adequação dos projetos pedagógicos dos Cursos de Pedagogia e Normal Superior, tendo em vista a Resolução CNE/CP n ${ }^{\circ} 1$ (CONSELHO NACIONAL DE EDUCAÇÃO, 2006).
} 
0 que se pode perceber é uma amplitude da atividade docente. Então definir o campo de atuação do pedagogo é definir o campo de atuação dos docentes da educação infantil e das séries iniciais, que não se restringirá ao trabalho docente, mas alcançará o trabalho pedagógico. Busca-se com esse movimento superar a dicotomia professor $X$ especialistas: nem circunscrever a formação docente num conjunto de metodologias de ensino ou conteúdos específicos para a docência, nem fomentar a fragmentação já prevista desde 1969 - com as diversas habilitações caracterizando na formação dos especialistas. Então,

A compreensão da licenciatura nos termos das DCN-Pedagogia, implicará, pois, uma sólida formação teórica, alicerçada no estudo das práticas educativas escolares e nãoescolares e no desenvolvimento do pensamento crítico, reflexivo fundamento na contribuição das diferentes ciências e dos campos de saberes que atravessam o campo da pedagogia (AGUIAR et al., 2006, p. 832).

Se as DCN-Pedagogia e as DCN para formação inicial em nivel superior dos professores da Educação Básica ampliam as perspectivas para o docente das séries iniciais do Ensino Fundamental, há que se notar o ponto vulnerável desse fundamento. Professores de um curso de Pedagogia apontaram sua preocupação com a resistência das alunas em relação ao exercício da docência, demonstrando que a amplitude na formação é incorporada pelas alunas como uma possibilidade de sair da sala de aula, ao invés de ser um caminho para potencializar a prática de ensino (OLIVEIRA, 2007). Assim, melhorar a formação dos professores ampliando seu campo de conhecimento e de possibilidades de atuação parece não encontrar, ainda, um diálogo com a construção da identidade e do trabalho docente. As diretrizes acabam por estimular os alunos a procurarem outros campos de atuação, por considerá-los mais bem remunerados e mais valorizados. Corroboro então com Lucíola Licínio de Castro Paixão Santos (2006), professora da FAE-UFMG, em entrevista dada à revista Presença Pedagógica: políticas públicas que não estão acopladas com uma melhoria no salário e na carreira dos professores acabam tendo pouco efeito.

As DCN-Pedagogia delimitam que a elaboração do Projeto Pedagógico, em torno das áreas ou modalidades de ensino, proporcionem um aprofundamento de estudos sempre a partir da formação comum da docência na Educação Básica. No que tange à organização curricular, merecem destaque:

- os estudos de teorias necessárias à construção de aprendizagem, socialização e elaboração de conhecimentos, de tecnologias da informação e comunicação e de diversas linguagens;

- a decodificação e utilização de diferentes linguagens utilizadas pelas crianças; 
- a participação em seminários, em projetos de iniciação científica;

- as atividades de comunicação e expressão cultural;

- a delimitação de horas para atividades teórico-práticas por meio da iniciação científica e para a participação em pesquisas.

Essas atividades se distribuiriam entre os três núcleos distintos na estrutura curricular dos cursos: núcleo de estudos básicos, núcleo de aprofundamento e diversificação de estudos e núcleo de estudos integradores. Parece que a definição desses núcleos visa a incorporar as perspectivas para a formação dos professores no Brasil e que, desde a década de 1990, vêm sendo enfatizadas em publicações da área (CARVALHO; SIMÕES, 2006), tais como: a busca de articulação entre a teoria e a prática; a construção da competência profissional aliada ao compromisso social do professor, a interdisciplinaridade curricular e o desenvolvimento de pesquisas.

A prática investigativa é apontada no documento como um dos elementos essenciais na formação docente, o que significa "[...] formar um profissional dotado de uma postura interrogativa e que se revele um pesquisador de sua própria ação docente" (DINIZ-PEREIRA, 1999, p. 118). As instituições devem estar atentas para a integralização de todas as práticas formativas realizadas nos cursos, visando a superar a valorização das disciplinas especificas sobre as disciplinas pedagógicas. Para superar a hierarquia entre as disciplinas, Diniz-Pereira (2006, p. 71) destaca o papel das "disciplinas integradoras", entendidas como aquelas disciplinas que fazem uma transposição do conhecimento da área para a realidade escolar, tendo um papel relevante "na articulação entre as disciplinas de conteúdo específico e as pedagógicas e na vinculação permanente das licenciaturas com ensino médio e fundamental".

As trajetórias curriculares para a formação docente indicam uma preocupação em formar o professor para a diversidade e para as transformações de uma sociedade influenciada pelo desenvolvimento científico-tecnológico. As professoras dos anos iniciais têm sua formação ampliada, no tocante ao nível de ensino e às demandas curriculares, face às especificidades dos alunos das diversas modalidades de ensino educação indígena, educação de jovens e adultos, educação especial, educação do campo. Considerando a publicação recente das DCN-Pedagogia, teremos que esperar um tempo para perceber os efeitos de tal amplitude na educação brasileira.

\section{Considerações finais}

A formação para a docência nos anos iniciais do Ensino Fundamental, em nível superior, cursos de licenciatura, graduação plena, constitui em um ganho no tocante a preparação desse profissional. No entanto, essa conquista não fica livre de críticas e análises mais aprofundadas por diversos educadores da área. Tais análises 
são necessárias, dado que a história do curso de formação da professora primária se relaciona com a expansão do ensino primário em uma proporção inversa entre quantidade e qualidade. Assim, o contexto verificado ante a criação da LDB 9394 (BRASIL, 1996) - e daquelas que a antecederam - é uma constatação da baixa escolaridade da maioria da população (primeiramente, atribuída à desqualificação do professor) frente a uma sociedade que se desenvolve, se urbaniza, e busca consolidar-se no cenário capitalista global.

Os condicionantes sócio-históricos das políticas públicas de formação docente nos fazem refletir sobre a melhoria educacional dos cidadãos "declarada" nas leis e diretrizes. Existe nessas propostas uma linha tênue entre o interesse de se melhorar a educação, com vistas à efetiva formação global, sólida e qualificada do cidadão, e uma melhora até o limite de responder aos anseios do desenvolvimento e acúmulo do capital, ou seja, uma formação mínima para trabalhadores a fim de se manter a estrutura econômica vigente. Sobre esta última perspectiva, Torres (1998, p. 175), ao delinear as tendências da formação docente nos anos 90 , denuncia a relação mecânica entre capacitação de professores e rendimento escolar presente nas políticas públicas, onde a escola "é uma fábrica que produz objetos, mercadorias, não um espaço e produção de conhecimento, aprendizagem e socialização".

Não obstante, é preciso tomar cuidado com o discurso de formação ampla adotado pelas políticas públicas. 0 avanço do conhecimento e da tecnologia, a globalização planetária, as novas linguagens de comunicação e informação, a diversidade social têm servido de fundamentação para a formulação de diretrizes, propostas pedagógicas e curriculares. Em contrapartida, pouca melhoria é verificada na carreira dos profissionais da educação, que continuam desdobrando-se em várias atividades no interior das instituições onde atuam, para lidar com a demanda de serviços presentes no processo educativo. Além disso, trabalham em dois ou três turnos para suprirem a defasagem salarial que marca a renda desta categoria profissional. Essa realidade é um obstáculo para o aprofundamento do educador nos estudos sobre o fenômeno educacional como um todo, em sua participação em pesquisas e debates de interesse para sua área profissional e na reflexão de suas atitudes enquanto docente. Mais ainda, é um fator que leva à desistência da profissão docente. 


\section{Referências}

AGUIAR, M. A. S. et al. Diretrizes Curriculares do Curso de Pedagogia no Brasil: disputas de projetos no campo da formação do profissional da educação. Educação e Sociedade, Campinas, SP, v. 27. n. 96, p. 819-842, out. 2006.

BRASIL. Decreto nº 3.276, de 6 de dezembro de 1999. Dispõe sobre a formação em nível superior de professores para atuar na educação básica, e dá outras providências. Diário Oficial da União, Brasília, DF, 7 dez. 1999.

. Decreto n .3 .554 , de 7 de agosto de 2000. Dá nova redação ao $\S 2^{\circ}$ do art. $3^{\circ}$ do Decreto $n^{\circ} 3.276$, de 6 de dezembro de 1999, que dispõe sobre a formação em nível superior de professores para atuar na educação básica. Diário Oficial da União, Brasília, DF, 8 ago. 2000.

. Lei $n^{\circ}$. 9.394, de 20 de dezembro de 1996. Estabelece as diretrizes e bases da educação nacional. Diário Oficial da União, Brasilia, DF, 23 dez. 1996.

. Ministério da Educação Plano de Desenvolvimento da Educação. Brasília, DF, 2007. Disponível em: < http://pde.mec.gov.br/>. Acesso em: maio 2007.

CARVALHO, J. M.; SIMÕES, R. H. S. Formação inicial de professores: uma análise dos artigos publicados em periódicos nacionais. In: ANDRÉ, M. (Org.). Formação de professores no Brasil (1990-1998). Brasília, DF: MEC/INEP/Comped, 2006.

CONSELHO FEDERAL DE EDUCAÇÃO (Brasil). Parecer nº. 251/62. Revista Documenta, Brasília, DF, n. 11, jan. 1963.

CONSELHO NACIONAL DE EDUCAÇÃO (Brasil). Parecer CNE/CP n. 115, de 10 de agosto de 1999. Diretrizes Gerais para os Institutos Superiores de Educação (Dispõe sobre os Institutos Superiores de Educação, considerados os Art. 62 e 63 da Lei 9.394/96 e o Art. 9, § 2, alíneas "c" e "h" da Lei 4.024/61, com a redação dada pela Lei 9.131/95). Diário Oficial da União, Brasilia, DF, 6 set. 1999.

. Parecer CNE/CP n 5, de 13 de dezembro de 2005. Diretrizes Curriculares Nacionais para o Curso de Pedagogia. Diário Oficial da União, Brasilia, DF, 15 maio 2006.

. Resolução CNE/CP nº. 1, de 15 de maio de 2006. Institui Diretrizes Curriculares Nacionais para o Curso de Graduação em Pedagogia, Licenciatura. Diário Oficial da União, Brasilia, DF, 16 de maio de 2006. Seção 1, p. 11. 
CURY, C. R. F. A formação docente e a educação nacional. In: OLIVEIRA, D. A. (Org.). Reformas educacionais na América Latina e os trabalhadores docentes. Belo Horizonte: Autêntica, 2003.

DIAS, V. C. 0 curso normal superior e a prática profissional de professoresalunos: da expectativa à realidade. 2003. 146 f. Dissertação (Mestrado em Educação) - Pontífica Universidade Católica de Minas Gerais, Belo Horizonte, 2003. Disponivel em: <http://www.pucminas.br>. Acesso em: 15 maio 2006.

DINIZ-PEREIRA, J. E. As licenciaturas e as novas políticas educacionais para a formação docente. Educação e Sociedade, Campinas, SP, v. 20, n. 68, p. 109-125, dez. 1999.

DINIZ-PEREIRA, J. E. A formação de professores nas licenciaturas: velhos problemas, novas questões. In: Formação de professores: pesquisas, representações e poder. 2. ed. Belo Horizonte: Autêntica, 2006.

FREITAS, H. C. L. Formação de professores no Brasil: 10 anos de embate entre projetos de formação. Educação e Sociedade, Campinas, SP, v. 23, n. 80, p. 136167, set. 2002.

FREITAS, H. C. L. A [nova] política de formação de professores: a prioridade postergada. Educação e Sociedade, Campinas, SP, v. 28, n. 100, p.1203-1230, out. 2007.

GOMES, M. G. F. M. Trajetória profissional: significados e saberes profissionais construídos pelas professoras cursistas do Curso Normal Superior Veredas. 2005. 224 f. Dissertação (Mestrado em Educação) - Pontífica Universidade Católica de Minas Gerais, Belo Horizonte, 2005. Disponível em: <http://www.pucminas.br>. Acesso em: 15 maio 2006.

LIBÂNEO, J. C.; PIMENTA, S. G. Formação de profissionais da educação: visão critica e perspectiva de mudança. Educação e Sociedade, v. 20, n 68, p. 239-277, dez. 1999. Disponivel em: <http://www.scielo.br>. Acesso em: 08/09/06.

LIBÂNEO, J. C. Pedagogia e Pedagogos, para quê?. 8. ed. São Paulo: Cortez, 2005. MAUÉS, 0. C. Reformas internacionais da educação e formação de professores. Cadernos de Pesquisa, São Paulo, n. 118, p. 89-117, mar. 2003.

NOVAES, M. E. Professora primária: mestra ou tia?. 5. ed. São Paulo: Cortez, 1992. 
OLIVEIRA, C. K. M. Pedagogia em crise de identidade. Presença Pedagógica, Belo Horizonte, v. 12, n. 71, p. 39-43, set./out. 2006.

OLIVEIRA, L. M. A licenciatura para a docência nos anos iniciais do ensino fundamental: possibilidades de uma educação tecnológica na formação do educador. 2007. 162 f. Dissertação (Mestrado em Educação Tecnológica) - Centro Federal de Educação Tecnológica de Minas Gerais, Belo Horizonte, 2007.

PALMA FILHO, J. C. A política nacional de formação de professores. In:

BARBOSA, R. L. L. (Org.). Trajetórias e perspectivas da formação de educadores. São Paulo: Ed. UNESP, 2004.

PIMENTA, S. G. Mesa redonda: por uma pedagogia de formação de professores: embates conceituais e critica das politicas atuais. In: BARBOSA, R. L. L. (Org.). Trajetórias e perspectivas da formação de educadores. São Paulo: Ed. UNESP, 2004.

SANTOS, L. L. C. P. [entrevista]. Presença Pedagógica, Belo Horizonte, v.12, n. 67, jan./fev. 2006.

TORRES, R. M. Tendências da formação de professores nos anos 90. In: WARDE, M. J. (Org.). Novas politicas educacionais: criticas e perspectivas. São Paulo: PUC/SP, 1998.

Recebido em: 16/10/2008

Aceito para publicação em: 29/01/2009 